\title{
Nueva interacción potencialmente peligrosa entre claritromicina y estatinas
}

\author{
Potentially dangerous interaction between clarithromycin and statins
}

Li DQ. CMAJ. 2015;187(3):174-80.

\section{Objetivo}

Determinar la incidencia de efectos adversos graves en pacientes que recibieron concomitantemente claritromicina y estatinas no metabolizadas por el citocromo P450 subtipo 3A4 (CYP3A4).

\section{Diseño, lugar y participantes}

Se realizó una cohorte de base poblacional (base de datos de la ciudad de Ontario, Canadá) de pacientes adultos mayores de 74 años que estaban consumiendo estatinas no metabolizadas por CYP3A4 (un $76 \%$ recibía rosuvastatina, un $21 \%$ pravastatina y un $3 \%$ fluvastatina) entre 2002 y 2013 y les fue prescripta claritromicina $(\mathrm{n}=51.523)$ o azitromicina $(\mathrm{n}=$ 52.518). La azitromicina no interactúa con otros transportadores hepáticos (ver comentarios) y fue tomada como droga índice (control) debido a su perfil de indicación similar al de la claritromicina. Se excluyeron pacientes con prescripciones de otras estatinas $u$ otros antibióticos en el mismo periodo, pacientes recientemente internados (para seleccionar sólo prescripciones ambulatorias) y pacientes que reciben otros inhibidores potentes del CYP3A4 (azoles, cloranfenicol o inhibidores de proteasa de HIV).

Los resultados medidos fueron hospitalizaciones con diagnóstico de rabdomiólisis, insuficiencia renal aguda o hiperpotasemia y mortalidad por todas las causas. Estos fueron tomados mediante códigos hospitalarios validados. Los resultados fueron evaluados dentro de los 30 días de la primera coprescripción y se ajustaron por las comorbilidades de los pacientes. No se evaluó el efecto de nuevas co-prescripciones.

\section{Resultados}

En comparación al grupo control (azitromicina), los pacientes con co-prescripción de claritromicina y estatinas no metabolizadas por CYP3A4 tuvieron un riesgo mayor de hospitalización por insuficiencia renal aguda (riesgo relativo [RR] ajustado 1,65; IC 95\% 1,31 a 2,09), hiperpotasemia (RR ajustado 2,17 ; IC $95 \% 1,22$ a 3,86) y mortalidad por todas las causas (RR ajustado 1,43; IC 95\% 1,15 a 1,76). EI RR ajustado para rabdomiólisis no fue significativamente mayor. En términos absolutos, el riesgo para cada resultado fue pequeño (menor a $1 \%$ ), aún considerando el subregistro hospitalario.

\section{Conclusiones}

En adultos mayores que toman estatinas no metabolizadas por CYP3A4, la co-prescripción de claritromicina en comparación con azitromicina estuvo asociada a un aumento modesto pero significativo del riesgo absoluto de efectos adversos graves.

Fuente de financiamiento: Institute for Clinical Evaluative Sciences Western (dependencia del Ministerio de Salud y Cuidados a Largo Plazo de Ontario).

\section{Comentario}

La claritromicina es un inhibidor del CYP3A4. La co-prescripción de claritromicina y estatinas metabolizadas a través del CYP3A4 (simvastatina, lovastatina y atorvastatina) aumenta el riesgo de miopatía por lo cual su uso combinado está contraindicado ${ }^{1}$. La claritromicina también es un inhibidor de otros transportadores hepáticos OATP1B1 y OATP1B3. La función de los mismos es captar sustratos orgánicos (como la bilirrubina) y fármacos y facilitar su traspaso a la bilis para su excreción. Existen otros inhibidores y sustratos de estos transportadores OATP1B1 (estatinas, carbamazepina, digoxina, eritromicina, gemfibrozil, glibenclamida, pioglitazona, rifampicina, sildenafil, inhibidores de proteasa de HIV, telmisartán y valsartán) y OATP1B3 (eritromicina, rifampicina) objeto de posibles interacciones farmacológicas a ser exploradas².

Este estudio aporta información clínica a estas hipótesis de interacciones farmacológicas generadas a partir del mayor conocimiento de la biología molecular. Sin embargo el estudio tiene limitaciones en términos del diseño de investigación (estudio retrospectivo, dependiente de bases de datos administrativas), y a su vez en términos de riesgo absoluto, el resultado es de poca magnitud.

Sin embargo los macrólidos suelen ser antibióticos prescritos de manera inadecuada para cuadros virales de vías aéreas superior o bronquitis agudas, donde tienen nula efectividad ${ }^{3}$. En este contexto, la prescripción prudente de antibióticos para la reducción de la resistencia bacteriana como estrategia poblacional suma una nueva razón para pensar cuidadosamente antes de indicar antibióticos ineficaces y posiblemente peligrosos.

\section{Conclusiones del comentador}

A la hora de indicar claritromicina en pacientes que reciben estatinas se debe considerar el beneficio terapéutico real estimado en relación a los riesgos que se conocen de la interacción. En el caso en que haya una fuerte indicación de recibir macrólidos, una alternativa más segura podría ser la azitromicina.

Juan Víctor Ariel Franco [ Servicio de Medicina Familiar y Comunitaria del Hospital Italiano de Buenos Aires. Departamento de Toxicología y Farmacología de la Universidad de Buenos Aires. Centro Cochrane del Instituto Universitario del Hospital Italiano de Buenos Aires. juan.franco@ hospitalitaliano.org.ar ]

Franco JVA. Nueva interacción potencialmente peligrosa entre claritromicina y estatinas. Evid Act Pract Ambul. 2016;19(3):90. Comentado de: Li DQ, y col. Risk of adverse events among older adults following co-prescription of clarithromycin and statins not metabolized by cytochrome P450 3A4. CMAJ. 2015;187(3):174-80. PMID: 25534598.

\section{Referencias}

1. US Food and Drug Administration. Safety Information for Biaxim (clarithromycin). Disponible en URL: http:/www.fda.gov/Safety/MedWatch/Safetylnformation/ucm258816.htm (fecha de último acceso 19/07/16)

2. Kalliokoski A, y col. Impact of OATP transporters on pharmacokinetics. British Journal of Pharmacology. 2009;158(3):693-705.

3. Gonzales R, y col. Principles of Appropriate Antibiotic Use for Treatment of Acute Respiratory Tract Infections in Adults: Background, Specific Aims, and Methods. Ann Intern Med. 2001;134:479486. 